\title{
A High Strength Ti-SiC Metal Matrix Composite
}

\author{
K. M. Rahman ${ }^{\mathrm{a}}$, V. A. Vorontsov ${ }^{\mathrm{a}}$, S. M. Flitcroft ${ }^{\mathrm{b}}$, D. Dye ${ }^{\mathrm{a}}$ \\ ${ }^{a}$ Department of Materials, Royal School of Mines, Imperial College London, Prince Consort Road, London SWr 2BP, UK \\ ${ }^{b}$ TISICS Ltd. 22 Invincible Road, Farnborough, Hampshire, GU14 7QU, UK
}

\begin{abstract}
A SiC reinforced Ti-5Al-5Mo-5V-3Cr matrix metal matrix composite was developed. Monolithic blocks of alloy were hot rolled via pack rolling to produce foils for MMC panel fabrication. These were consolidated using hot isostatic pressing and solution treated and aged for optimum strength. The panels exhibited a strength of $2 \mathrm{GPa}$ in tension and $3.5 \mathrm{GPa}$ in compression, compared to the aerospace steel $300 \mathrm{M}$, which has a tensile strength of $1.69 \mathrm{GPa}$. The fatigue performance of the material exceeded that of MMCs developed using Ti-21S or Ti-6Al-4V matrices. Finally, the reaction zone between the $\mathrm{SiC}$ and matrix was examined, revealing the presence of $\mathrm{TiC}$.
\end{abstract}

Key words: Metal Matrix Composites, Fatigue, Strength, Mechanical Testing, Isostatic processing

\section{Introduction}

Metal matrix composites (MMCs) provide superior properties compared to monolithic materials, typically having ${ }_{30}^{38}$ higher strength and stiffness while reducing density [1]. MMCs generally exist in two forms: continuous fibre and particle reinforced composites. The former, although more ${ }^{41}$ expensive, provides the most effective strengthening in $a^{42}$ specific direction [2]. Improvements in strength and stiff- ${ }^{43}$ ness, while reducing weight, allow dimensional and mass ${ }_{45}^{44}$ reductions in components. Thus, MMCs have received ex- ${ }^{45}$ tensive research interest and are extremely attractive for ${ }_{47}^{46}$ industrial use [2-4].

A variety of MMCs have been developed utilising differ- ${ }^{48}$ ent reinforcement and matrix materials. Reinforcements ${ }^{49}$ are available in the form of continuous and short fibres, ${ }^{50}$ whiskers and particles, where continuous fibres have an as- ${ }^{51}$ pect ratio approaching infinity [5]. MMC reinforcements ${ }_{53}^{52}$ range from carbon, boron, oxides e.g. alumina and non- ${ }^{53}$ oxides e.g. SiC. Some fibres have significant anisotropy, ${ }^{54}$ making polycrystalline fibres such as SiC attractive [6].

Titanium alloys combine light weight, high strength ${ }^{56}$ and good chemical resistance, leading to extensive use in ${ }^{57}$ engineering components $[7,8]$. These attributes make tita- ${ }^{58}$ nium an excellent matrix material in MMCs. Although the ${ }^{59}$ most commonly used aerospace titanium alloy is the $\alpha+\beta^{60}$ alloy Ti-6Al-4V [9-11], metastable $\beta$ alloys such as Ti-5Al- ${ }^{6}$ $5 \mathrm{Mo}-5 \mathrm{~V}-3 \mathrm{Cr}$ offer significant improvements in strength $(>1.4$ GPa) [12]. Metastable $\beta$ alloys are able to maintain good ${ }^{63}$ properties throughout thick sections, e.g. for large com- ${ }_{65}^{64}$ ponents [13]. The lower $\beta$ transus temperature in alloys ${ }^{65}$ such as Ti-5-5-5-3 ( $\left.\sim 845^{\circ} \mathrm{C}\right)$ also enables processing at ${ }^{66}$ lower temperatures, reducing associated energy costs $[14$, 15]. In addition, Ti-5-5-5-3 has processing advantages over older high strength $\beta$ alloys such as Ti-3Al-8V-6Cr-4Mo$4 \mathrm{Zr}$ (Beta-C). Beta-C is stronger than Ti-5-5-5-3 in the cold rolled and aged condition where dislocations are used to nucleate fine $\alpha$ precipitates. However, Ti-5-5-5-3 is stronger in the forged condition. Since Beta-C requires cold work to maximise strength, which is not feasible in the production of large components, the alloy is restricted to applications such as springs.

Several techniques exist for producing Ti-MMCs $[16$, 17], including; fibre-foil-fibre (FFF), matrix coated mono tape (MCM) and matrix coated fibre (MCF) methods. $\mathrm{MCF}$ is most commonly manufactured via physical vapour deposition (PVD) [18], depositing matrix material onto single fibres, which are then packed into arrays and consolidated by hot isostatic pressing (HIPing) or vacuum hot pressing to form the composite. This production route has the disadvantage of being expensive due to the need for molten metal. The FFF technique uses alternately stacked layers of matrix foil and fibre mat. The array is then consolidated to produce the MMC. Material produced using the FFF method will exhibit good tensile strength and fracture toughness, but suffers from microstructural heterogeneity, giving rise to poorer fatigue performance than MCF methods. The major drawback of the FFF method is the lack of availability of high quality matrix foil for most alloys.

The current study investigates the benefit of using a Ti-5-5-5-3 matrix in a SiC fibre reinforced MMC. The overriding objective is to develop the strongest MMC possible, utilising feasible processing routes. Monolithic matrix material was pack rolled to produce foil to consolidate with SiC fibres to form the MMC. A range of heat treatments were employed to maximise mechanical properties. In addition, microscopy was conducted to augment the results. 


\section{Experimental Procedures}

Matrix foil was produced from Ti-5-5-5-3 blocks that ${ }_{124}$ were vacuum encapsulated within a $20 \times 100 \times 60 \mathrm{~mm}$ steel $_{125}$ frame. These blocks were hot rolled at $810^{\circ} \mathrm{C}$, to a $\mathrm{fi}^{126}$ nal reduction of $90 \%$. A 5 min interpass time was used ${ }_{127}$ for reheating the billet. Once rolled the steel frame was evacuated, the titanium was sectioned, coated in yttria, ${ }_{129}$ re-stacked and encapsulated for further rolling, until foil ${ }_{130}$ with a nominal thickness of $140 \mu \mathrm{m}$ was obtained.

The silicon carbide fibre used in this investigation was $^{131}$ supplied by TISICS Limited, variant SM3156, which had a $\mathrm{a}_{133}$ nominal fibre diameter of $140 \mu \mathrm{m}$ with a minimum strength $_{134}$ of $3.8 \mathrm{GPa}$.

The FFF approach was used to consolidate MMC panels via HIPing at $840{ }^{\circ} \mathrm{C}$ for $5 \mathrm{~h}$. The panels were manufactured with a $39 \%$ fibre volume fraction $\left(V_{f}\right)$ and had $\mathrm{a}_{138}$ thickness of $5 \mathrm{~mm}$.

Samples for mechanical testing were produced using ${ }_{140}$ electric discharge machining. $10 \mathrm{~mm}$ wide strips were pro- ${ }_{141}$ duced for tensile testing and $4 \times 4 \times 5 \mathrm{~mm}$ blocks for com- ${ }_{142}$ pression. Testing was conducted on a Zwick Roell $100 \mathrm{kN}_{143}$ load frame at a nominal strain rate of $1 \times 10^{-4} \mathrm{~s}^{-1}$. Fatigue testing was conducted using sinusoidal loading at ${ }_{145}$ an $\mathrm{R}$ ratio of 0.1 and a frequency of $5 \mathrm{~Hz}$ under a maxi- ${ }_{146}$ mum applied stress ranging between $40-75 \%$ of the tensile ${ }_{147}$ strength. Loading was applied parallel to the fibre direc- ${ }_{148}$ tion for all the mechanical testing. Tensile testing was $_{149}$ conducted on 6 specimens to account for scatter, similarly ${ }_{150}$ 3 samples were tested in compression and 3 samples were ${ }_{151}$ tested in fatigue for each maximum applied stress.

Samples for transmission electron microscopy were prepared using Focussed Ion Beam (FIB) milling on a $\mathrm{FEI}_{154}$ Helios NanoLab 600 series Dual Beam microscope. Elec- ${ }_{155}$ tron backscatter diffraction (EBSD) and imaging was con- ${ }_{156}$ ducted on a Zeiss Auriga FEGSEM equipped with a Bruker ${ }_{157}$ EBSD system. Scanning transmission electron microscopy ${ }_{158}$ (STEM) was conducted on a JEOL JEM-2100F microscope.

\section{Results and Discussion}

$\mathrm{g}$ gested that the $\beta$ to $\alpha$ phase transformation followed the
expected Burgers orientation relationship; $\{110\}_{\beta} / /(0001)_{\alpha}$ and $\langle 111\rangle_{\beta} / /[2 \overline{1} \overline{1} 0]_{\alpha}$.

Test MMC panels composing of a 5-ply layup were fabricated and an essentially defect-free microstructure was observed. Pores were not observed between foil layers and excellent wetting between the $\mathrm{SiC}$ and matrix was found. The matrix material formed a continuous bond with the C layer coating the SiC, Figure 2(c).

Figure 2(e-f) shows the microstructure observed when HIPed above the $\beta$ transus. Here, large $\beta$ grains can be seen interlinking the fibres, with grain boundary $\alpha$ often found nearly continuously linking the fibres. In titanium alloys, such grain boundary $\alpha$ is typically found to result in inferior ductility and fatigue strength [21]. In addition, a line between the matrix layers can be seen in Figure 2(f) which is due to the incomplete bonding between the individual matrix foils. These defects were not observed in the sub-transus MMC panels.

The ductility of a MMC is limited by that of the fibre. Therefore, for the purposes of maximising strength, the MMC panels were solution treated and aged (STA) to increase the matrix strength. The panels were solution treated at $840^{\circ} \mathrm{C}$ for $30 \mathrm{~min}$ followed by air cooling, aged at $580^{\circ} \mathrm{C}$ for $8 \mathrm{~h}$ and then air cooled again. This resulted in a microstructure composed of fewer globular primary $\alpha$, $\sim 2 \mu \mathrm{m}$ in size and a large fraction of $<20 \mathrm{~nm}$ fine secondary $\alpha$ laths for strengthening, Figure 2(c-d).

Heat treating close to the $\beta$ transus results in a lower fraction of primary $\alpha$, which does not significantly contribute to improving strength. This also means that a higher concentration of $\alpha$ stabilisers, e.g. Al, remain in solution that are available to precipitate fine scale secondary $\alpha$ laths during ageing. Fanning et al. [12, 21, 22] have reported peak tensile strengths in Ti-5-5-5-3 of 850$950 \mathrm{MPa}$ in the solutionised condition, which increases to

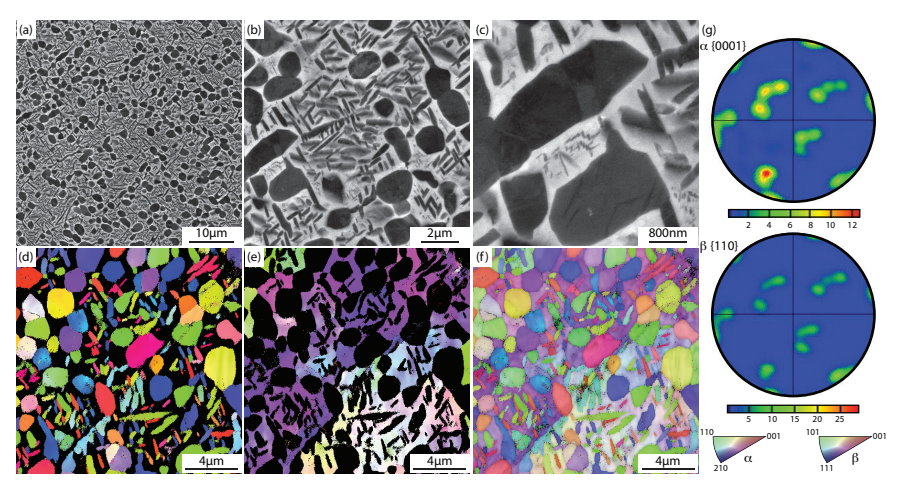

Figure 1: Initial microstructure of the Ti-5553 matrix material showing (a) distribution of globular primary alpha, (b,c) with fine secondary acicular alpha, (d) EBSD map of the hexagonal alpha phase with inverse pole figure (IPF) colouring (e) IPF coloured map of the cubic beta phase, (f) IPF coloured map of the microstructure composed of both alpha and beta and (g) alpha $\{0001\}$ and beta $\{110\}$ poles figures. IPF colouring is referred to the sample surface normal. 
$\sim 1400 \mathrm{MPa}$ once aged. Higher strengths were reported when the material was aged at lower temperatures, i.e. $560-680^{\circ} \mathrm{C}$. This is due to the formation of finer $\alpha$ laths which provide more interfaces and increase strength. However, low temperature ageing has a detrimental effect on ductility and toughness. When considering application in a MMC these shortcomings can be negated. Firstly, the ductility of the MMC will be dictated by the fibre. Finally, toughness and resistance to crack growth will be enhanced due to the extensive crack bridging facilitated by unbroken fibres [23].

An interfacial reaction zone less than $1 \mu \mathrm{m}$ in thickness arising from the reaction between the carbon layer and the Ti-5-5-5-3 matrix during fabrication of the $\mathrm{MMC}^{176}$ was observed, Figure 3. A TEM foil was lifted out from ${ }^{177}$ the region and imaged. Energy Dispersive X-ray Spec-178 troscopy (EDS) was used to collect elemental maps from ${ }^{179}$

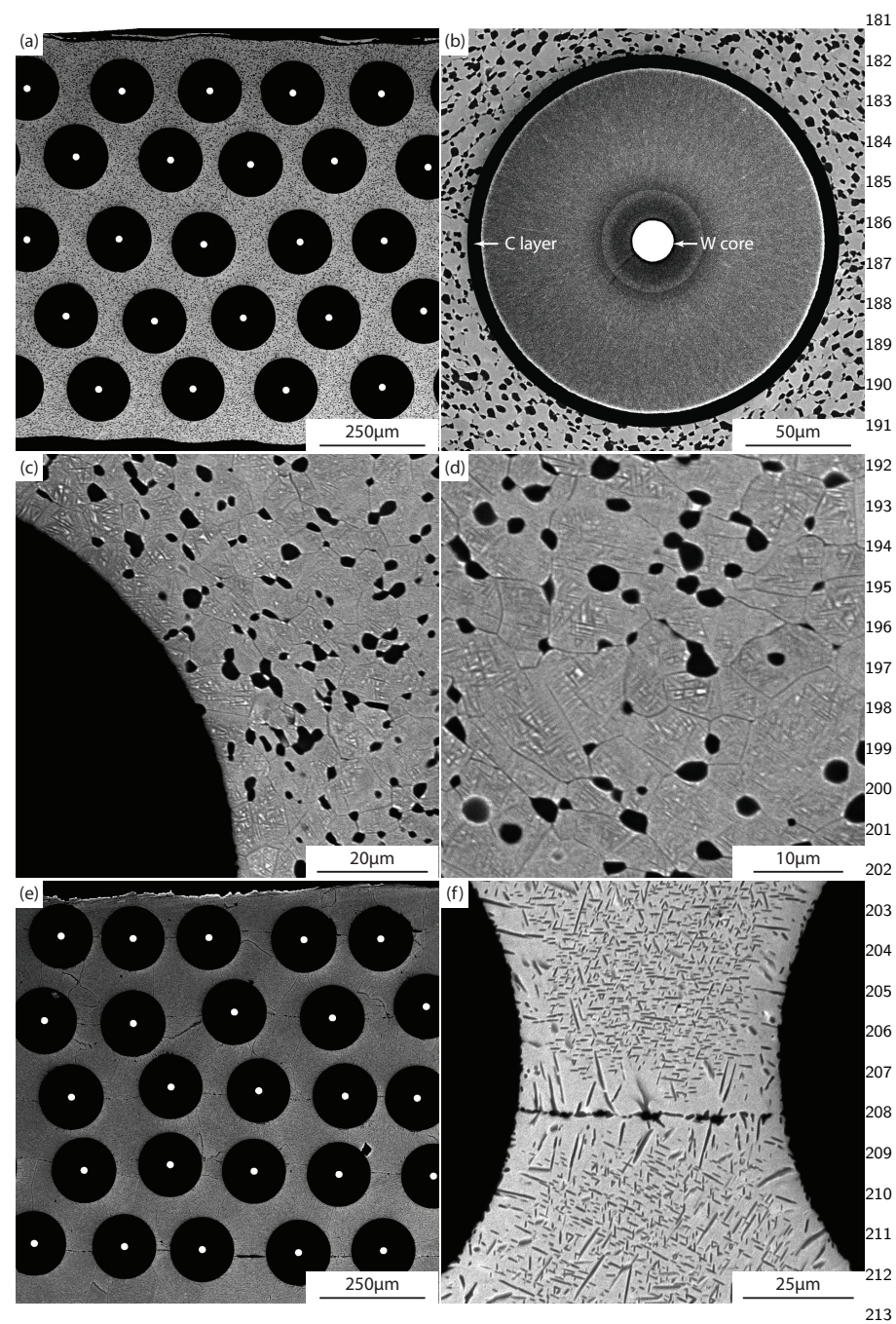

Figure 2: (a-d) Microstructure of a 5-ply MMC panel HIPed at $840^{\circ} \mathrm{C}^{214}$ showing (a) overview of the matrix and fibres, (b) interaction be-215 tween SiC fibre and matrix Ti-5553. The W core and C layer around ${ }_{216}$ the $\mathrm{SiC}$ is also observed (image has been composited in order to manage the contrast between the fibre and matrix), (c) globular primary ${ }^{217}$ alpha for retarding grain growth and (d) fine scale secondary alpha ${ }^{218}$ for strengthening. (e-f) Panel HIPed at $910{ }^{\circ} \mathrm{C}$, above the $\beta$ transus.219

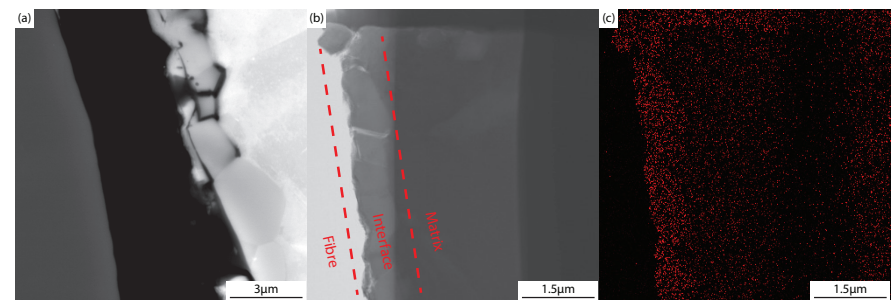

Figure 3: Interfacial reaction zone between carbon layer surrounding $\mathrm{SiC}$ and titanium matrix imaged using (a) secondary electron imaging, (b) bright field TEM and (c) corresponding carbon EDS map $(\mathrm{K} \alpha 1)$.

the region to visualise chemical segregation. The element mapping clearly illustrates the formation of $\mathrm{TiC}$ in the reaction zone. $\mathrm{Fu}$ et al. [28] have reported the formation of TiC in a Ti-6-4 - SiC MMC, while Huang et al. [29] have reported the presence of a $\mathrm{Ti}_{5} \mathrm{Si}_{3}$ layer also in a Ti-6-4 $\mathrm{SiC}$ MMC. The current investigation found no evidence of a distinct phase in the reaction zone in the present case.

The mechanical performance of the MMC panels was tested in both compression and tension, Table 1. The tensile strength was $\sim 2 \mathrm{GPa}$ with an elastic modulus of $200 \mathrm{GPa}$. Similarly the strength in compression was found to be $\sim 3.5 \mathrm{GPa}$. These properties are superior to similar MMCs reported in the literature including $\mathrm{Ti}$ and $\mathrm{Al}$ matrix composites [24, 25]. Baik [25] has reported a tensile strength of $1.2 \mathrm{GPa}$ in a $\mathrm{Ti}-6-4 / \mathrm{SiC}$ reinforced composite, which is significantly lower than the current study even after considering differences in fibre $V_{f}$. A Ti-21S (Ti-15Mo$3 \mathrm{Nb}-3 \mathrm{Al}-0.2 \mathrm{Si}$ - metastable $\beta$ alloy) MMC panel was also produced during the present study for comparison; the Ti-5-5-5-3 MMC was found to be $\sim 350 \mathrm{MPa}$ stronger in tension. This is most likely because the dislocation content required for Ti-21S to precipitate fine scale $\alpha$ during ageing cannot be retained through the HIP cycle; the ability of Ti-5-5-5-3 to produce fine scale $\alpha$ after hot working is the reason for selection of this alloy as the matrix material. In addition, Table 2 compares the strength of MMCs consolidated using various Ti matrix alloys by the authors, which have been normalised for a $33 \% V_{f}$. Here, it can clearly be seen that Ti-5-5-5-3 results in the highest strength yet attained in this system, with a density $\rho=3.90 \mathrm{~g} \mathrm{~cm}^{-3}$. Although, the alloy Beta-C attains a similar tensile strength, this can only be achieved in the cold rolled and aged condition which is not suitable for most engineering applications. For many aerospace structures of interest, Ti-MMCs would substitute for a martensitic steel such as $300 \mathrm{M}$, which has a density $\rho=7.87 \mathrm{~g} \mathrm{~cm}^{-3}$, a yield strength of $1690 \mathrm{MPa}$ and also requires corrosionresistant coating with $\mathrm{Cd}$-containing paints. Therefore the specific strength of the present Ti-MMC is approximately 2.4 times greater, with $39 \% V_{f}$

The fatigue behaviour of the Ti-5-5-5-3 MMC compared to Ti-21S matrix panels is shown in Figure 4 . The peak stress was selected at increasing proportions of the tensile stress, ranging from 40-75\% (800-1500 MPa). The 
Table 1: Mechanical properties of the MMC panel tested in tension and compression.

\begin{tabular}{lccc}
\hline Test Mode & Stiffness & Max. Stress & Failure Strain \\
& GPa & $\mathrm{MPa}$ & $\%$ \\
\hline Tension & 200 & $2050 \pm 110$ & 1.0 \\
Compression & - & $3500 \pm 60$ & 0.8 \\
\hline
\end{tabular}

Table 2: Comparison of the tensile strength of various Ti matrix MMCs normalised for a $33 \%$ volume fraction $\left(V_{f}\right)$ of fibres. SiC fibres used were from TISICS Limited, variant SM1140+, $100 \mu \mathrm{m}$ diameter, minimum strength $3.5 \mathrm{GPa} .{ }^{*}$ Beta-C strength calculated using a rule of mixtures method.

\begin{tabular}{cc}
\hline Matrix & Tensile Strength \\
& ${ }^{24}$ \\
Ti-6V-4Al & 1620 \\
Ti-15V-3Sn-3Cr-3Al & 1610 \\
Ti-15Mo-3Nb-3Al-0.2Si (Ti-21S) & 1625 \\
Ti-6Al-2Sn-4Zr-2Mo & 1635 \\
Ti-5Al-5Mo-5V-3Cr (super transus) & 1820 \\
Ti-5Al-5Mo-5V-3Cr (sub transus) & 1920 \\
Ti-3Al-8V-6Cr-4Mo-4Zr (Beta-C)* & 1920 \\
\hline
\end{tabular}

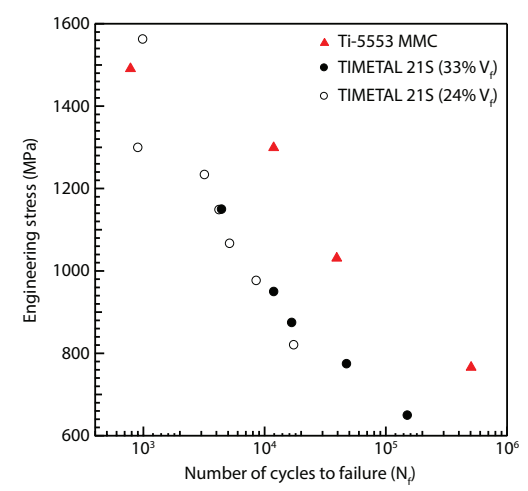

247

Figure 4: Fatigue properties of the MMC panel compared to Ti-21S $\mathrm{S}^{258}$ which had a tensile strength of $\sim 1.6 \mathrm{GPa}$.

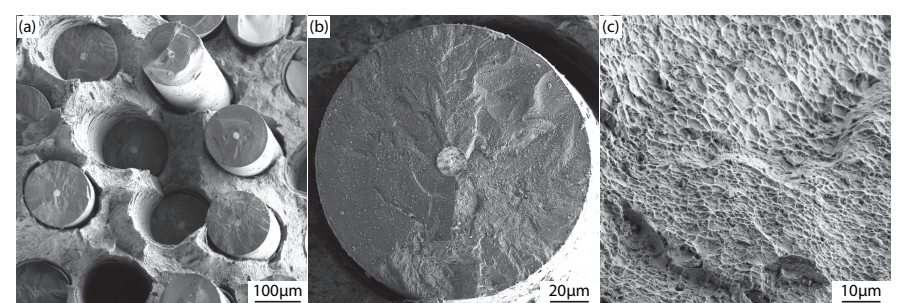

Figure 5: Fracture surface of the tensile test specimen exhibiting (a) fibre pull out, (b) cleavage of the brittle silicon carbide reinforcement and (c) void coalescence indicating ductile failure of the Ti-5-5-5-3 matrix.

was tested to a peak stress of $800 \mathrm{MPa}$ and accumulated an excess of 550,000 cycles before failure. The surface reveals the presence of ledges, Figure $6(\mathrm{a})$, which results from crack deflection during loading. The boundary of these ledges is decorated with fibres that have undergone pull out and are most likely due to either localised bending, shear or compression of the fibres on the ledge. Examination of the fracture surface suggests that the initiation point for failure originated at the SiC fibres that were located on the edge of the test specimen, Figure 6(b). During loading these fibres were cleaved, resulting in the appearance of planar facets in the matrix surrounding the fibre, Figure 6(c). Away from the initiation surface the matrix exhibits striations and the presence of void coalescence in the central region of the specimen, Figure $6(\mathrm{~d}, \mathrm{e})$.

\section{Conclusions}

In summary, a Ti-5-5-5-3 - SiC reinforced MMC was developed using a combination of pack rolling to produce metal foil, and a foil-fibre-foil layup method. The forged Ti-5-5-5-3 used in hot rolling was composed of globular primary $\alpha$ precipitates coupled with $<50 \mathrm{~nm}$ acicular secondary $\alpha$ laths. The texture was typical for a forged component exhibiting a Burgers type orientation relationship. The reaction zone between the fibre and matrix revealed a TiC layer. The MMC panels were solution treated and aged to optimise strength. This resulted in a $2 \mathrm{GPa}$ tensile strength and $3.5 \mathrm{GPa}$ flow stress in compression. The fatigue properties were excellent, requiring an excess of 550,000 cycles before failure at $800 \mathrm{MPa}$.

\section{Acknowledgements}

The authors would like to thank R. P. Durman and S. Kyle-Henney from TISICS Limited, Farnborough, UK, for material supply and production of the MMC panels. This work was part-funded by the Technology Strategy Board under grant TS/L000288/1 131238.

\section{References}

[1] N. Chawla, Y.-L. Shen, Adv. Eng. Mater. 2001, 3, 357. 


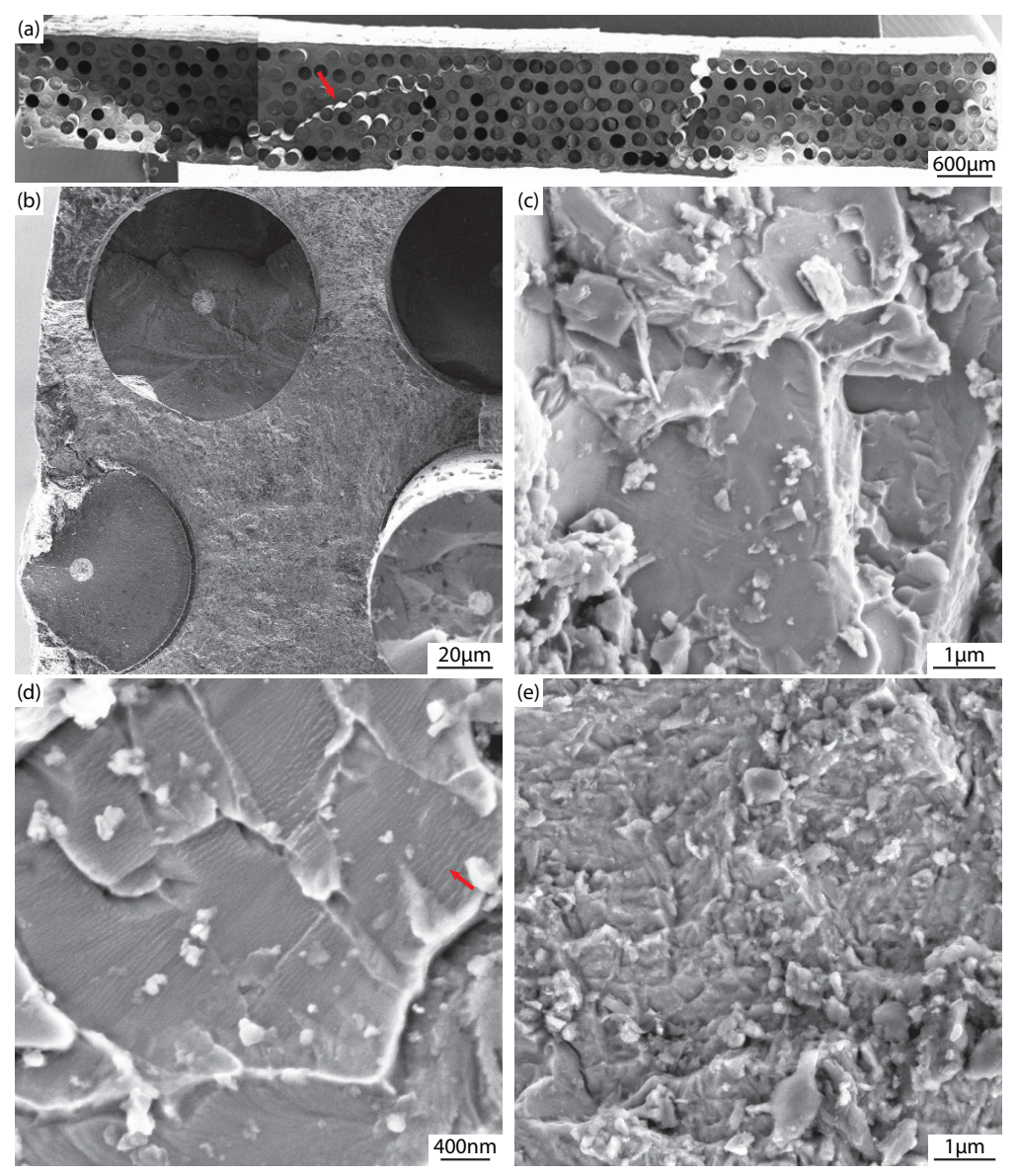

Figure 6: Fracture surface of specimen fatigue tested to a peak stress of $800 \mathrm{MPa}$ showing (a) overview of the sample (arrow indicates ledges), (b) cleavage of the brittle silicon carbide reinforcement with the suspected initiation region, (c) planar facets located near the fibres, (d) striations further into the sample (indicated with arrow) and (e) void coalescence.

[2] S.R. Bakshi, D. Lahiri, A. Agarwal, Int. Mater. Rev. 2010, 55,306 41.

[3] S. Rawal, J. Mater. 2001, 14.

[4] N. Takahashi, T. Sato, S. Nakatsuka, K. Fujiwara, K. Yoshida, 309 T. Yokozeki, Int. Congr. Aeronaut. Sci. 2012, 1, 1.

[5] A. Mortensen, J. Llorca, Annu. Rev. Mater. Res. 2010, 40,311 243.

[6] N. Chawla, K.K. Chawla, Metal Matrix Composites, 2nd Edi-313 tion, Springer, 2014.

[7] R. Boyer, R. Briggs, J. Mater. Eng. Perform. 2005, 14, 681. 315

[8] M. Peters, J. Kumpfert, C. Ward, C. Leyens, Adv. Eng. Mater. 316 2003, 5, 419.

[9] S. L. Semiatin, V. Seetharaman, A. K. Ghosh, Philos. Trans.318 R. Soc. A: Math. Phys. Eng. Sci. 1999, 357, 1487.

[10] S. L. Semiatin, T. R. Bieler, Acta. Mater. 2001, 49, 3565. 320

[11] A. K. Jha, S. K. Singh, M. S. Kiranmayee, K. Sreekumar,321 P. Sinha, Eng. Fail. Anal. 2010, 17, 1457.

[12] J. Fanning, J. Mater. Eng. 2005, 14, 788.

13] N. G. Jones, M. Jackson, Mater. Sci Tech 2011, 27, 1025

[14] N. G. Jones, R. Dashwood, D. Dye, M. Jackson, Metall. Mater. Trans. 2009, 40, 1944

[15] N. G. Jones, R. Dashwood, M. Jackson, D. Dye, Acta. Mater. 2009, 57, 3830

[16] Z. X. Guo, B. Derby, Prog. Mater. Sci. 1995, 411.

[17] C. M. Lobley, Z. X. Guo, Mater. Sci. Tech. 1998, 14, 1024.

[18] H. X. Peng, J. Mater. Sci. Tech. 2005, 21, 647.

[19] S. Shekhar, R. Sarkar, S. K. Kar, A. Bhattacharjee, Mater. Des. 2015, 66, 596.

[20] F. H. Froes Titanium: Physical Metallurgy, Processing, and
Applications, ASM International, 2015.

[21] J. Fanning, R. Boyer, World Conference on Titanium. 2003, 1, 2643.

[22] J. Fanning, S. L. Nyakana, K. M. Patterson, R. C. McDaniel, Ti-2007 Sci. Tech. 2007, 1, 499.

[23] D. L. Davidson Southwest Research Institute, San Antonio, TX,1989, 1 .

[24] P. Ashwath, M. A. Xavior, Processing methods and property evaluation of $\mathrm{Al} 2 \mathrm{O} 3$ and $\mathrm{SiC}$ reinforced metal matrix composites based on aluminium 2xxx alloys. J. Mater. Res. 2016;31;12011219. J. Mater. Res. 2016, 31, 1201.

[25] K. H. Baik Mater. Trans. 2006, 47, 2815.

[26] B. Lerch, G. Halford, Mater. Sci. Eng. A. 1995, 200, 47.

[27] B. P. Sanders, S. Mall, R. B. Pittman, Composites Sci. Tech. 1999, 59, 583.

[28] Y. Fu, N. Shi, D. Zhang, R. Yang, Mater. Sci. Eng. A. 2006, 426, 278.

[29] B. Huang, M. Li, Y. Chen, X. Luo, Y. Yang, Mater. Charact. 2015, 109, 206. 